\title{
Research and Design of Energy Efficiency Monitoring System for Resource-Saving Campus
}

\author{
Ling Cao ${ }^{a}$, Xiangwei Luo ${ }^{b}$, Jie Deng ${ }^{c}$, Weixin Chen ${ }^{d}$, Yan Zhao ${ }^{e}$, Junyi Yang ${ }^{f}$ \\ Chongqing University of Posts and Telecommunic0ations, Chongqing 400065, China. \\ acaoling@cqupt.edu.com, b1060900859@qq.com, c953838792@qq.com, dvanson152@163.com, \\ edubito8023@gmail.com, fhaofnhm960826@163.com
}

Keywords: Energy efficiency monitoring, Resource-saving campus, Energy management

\begin{abstract}
The state advocates building a "two-type society", while the education administration vigorously promotes "two-type campus" and provides corresponding policy support. Institutions of higher learning are an important part of society, and the construction of two-type campus in colleges and universities is an inevitable result of social development. Campus energy efficiency monitoring system is the premise and cornerstone of energy statistics, auditing and tracking. Reading energy consumption data from the energy metering device and ensuring stable and reliable data transmission to the upper data center can effectively grasp the energy consumption status of the building, find out the energy consumption problem, accurately provide the specific data of the terminal energy consumed by the building, accurately describe the characteristics of building energy consumption, and provide data support for determining the building energy quotas system and formulating the building energy over-quota fare increase system, which has an extraordinary significance to schools' energy-saving management and energy-saving retrofit.
\end{abstract}

\section{Introduction}

In June 2010, the Ministry of Housing and Urban-Rural Development promulgated the "Notice on Practically Strengthening Energy-Saving Management of Government Offices and Large Public Buildings", and demanded that all localities should, in light of their local actual conditions, further promote the construction of energy consumption monitoring systems for office buildings and large public buildings of state organs, make haste to establish the system of sound government office buildings and public buildings of room temperature monitoring and energy-saving operation management, and actively explore the establishment of energy-saving management incentive system of public buildings. The state advocates building a "two-type society", while the education administration vigorously promotes "two-type campus " and provides corresponding policy support. Building a "two-type society" is an important decision made by the party and the state in complying with the historical development. Institutions of higher learning are an important part of society, and the construction of two-type campus in colleges and universities is an inevitable result of history development, while implementing energy conservation and pollution emissions reduction $[3,4]$ and building a "green campus" have become a long-term and arduous task for institutions of higher learning.

Campus energy efficiency monitoring system, carrying out the thoughts of the green and low-carbon development in various aspects of university education, taking full account of the campus energy characteristics, is an integrated information-based energy management control system of energy monitoring and energy information management. For the actual use of energy of campus buildings, such as lighting, air conditioning, power, power distribution and other energy systems, the system, mainly through energy data collection instruments, DTU and other related hardware, real-time monitors all energy-using equipment of buildings, which is convenient for schools to effectively grasp the situation of energy consumption. The system presents the energy consumption analysis to the energy management party in the form of easy-to-understand visualization trends and reports, which enables the energy management agency to effectively grasp the energy consumption 
status of the building. At the same time, the system, a system of campus energy uses according to the basic principles of flatness, high efficiency, centralized and highly integrated, takes full account of the convenience of equipment maintenance. Once the energy management department discovers abnormal energy use, it can promptly notify the maintenance personnel to deal with the problem.

\section{The Overall System Design}

System design: green campus energy efficiency testing system, will fully integrate with the school's actual use of energy, under the principles of ensuring that the system to complete the basis of arrangement and step-by-step implementation, gradually improving the status of energy use in the campus, to establish a dynamic energy efficiency of the campus testing system. For the main energy-using buildings, the system conducts the energy by buildings and items, collects and collates the school energy data, analyzes, compares, publicizes, warns and forecasts, and develops a code of conduct for energy-using in schools. On the basis of realizing the function of energy consumption data acquisition, the system will reserve interfaces to meet the docking requirements between the system and national and provincial energy-saving regulatory platforms. At the same time, the system focuses on improving the energy efficiency of higher education institutions and aims at building a green campus and conserving the campus. It quantifies the goal of energy conservation in accordance with the overall quantitative management.

System design ideas: Based on embedded and Internet of Things technology, the system real-time acquires campus energy consumption data, real-time monitories the total energy consumption of campus and building energy consumption of major campus buildings by buildings and items, centralized uploads to consumption of data centers with TCP / IP protocol. After data integration, it through the server displays the data of various functions on WEB.

The overall system architecture is shown below:

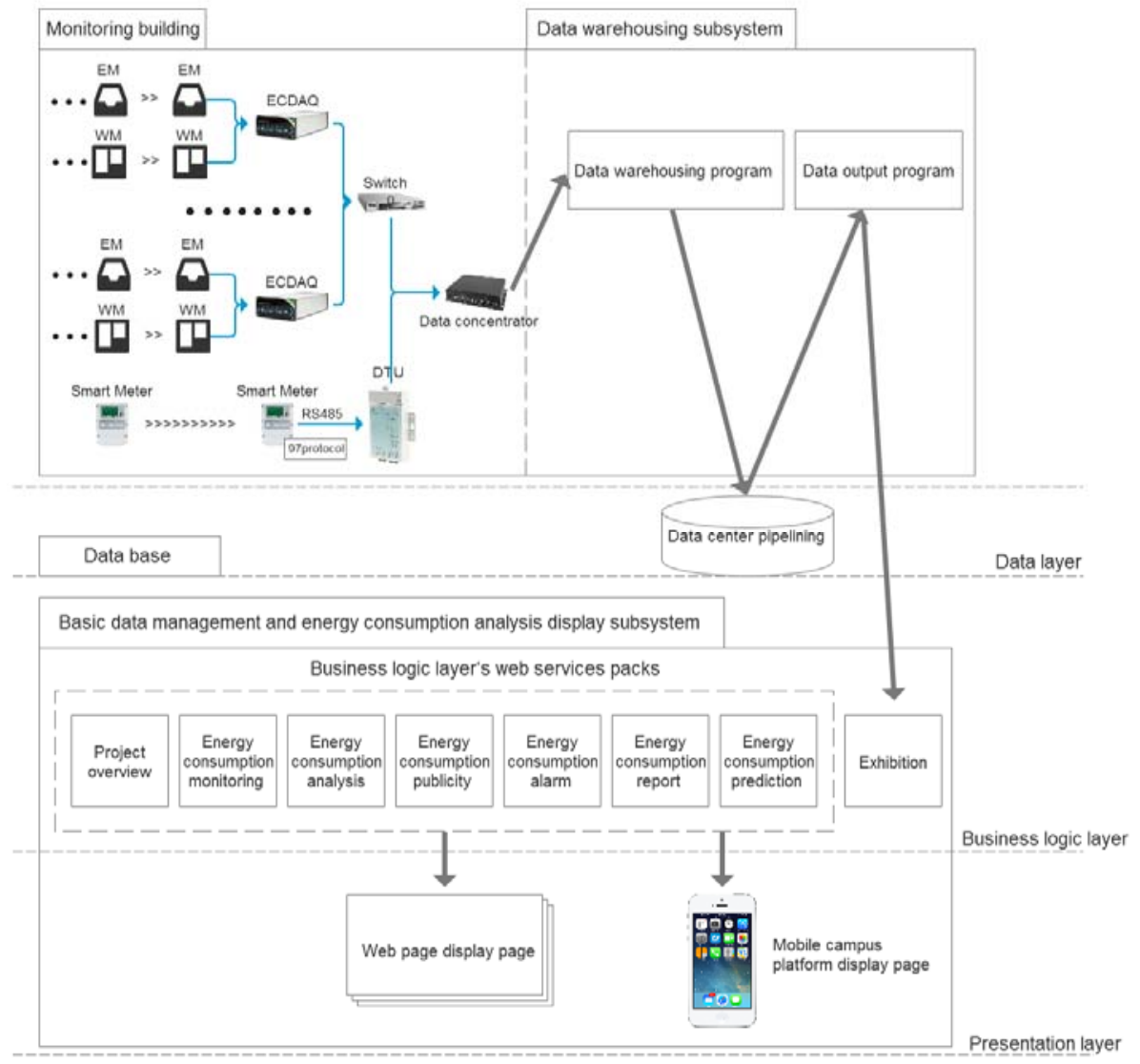

Fig. 1 Green campus energy efficiency monitoring overall system architecture diagram

System Hierarchical Design: In accordance with the functional system, energy efficiency testing system has the following four subsystems: 
Energy consumption data acquisition subsystem

Data storage subsystem

Basic data management subsystem

WEB display subsystem

Among them, the energy consumption data acquisition subsystem implements mainly the work of energy consumption data collection of various smart meters, such as electric energy meters and water meters. After the data is processed and processed uniformly, the data storage subsystem is responsible for storing the data in the energy efficiency system database and processing the data to calculate the total energy consumption of the campus as well as the energy consumption of sub-households and sub-projects at a certain time interval information. The basic data management subsystem manages various configuration information. WEB display subsystem, in the form of web pages, show detailed energy information, easy to analyze and make decisions. Divided according to the data flow, energy efficiency testing system can be divided from top to bottom: data layer, logical layer and presentation layer.

Data layer: The function of this layer is to collect the original data of the meter and to unify the storage.

Logical layer: The role of this layer is to extract the data in the database information, processing and binding to the presentation layer.

Presentation layer: The role of this layer is to display energy consumption with the ring, publicity, warning, forecasting and other related information.

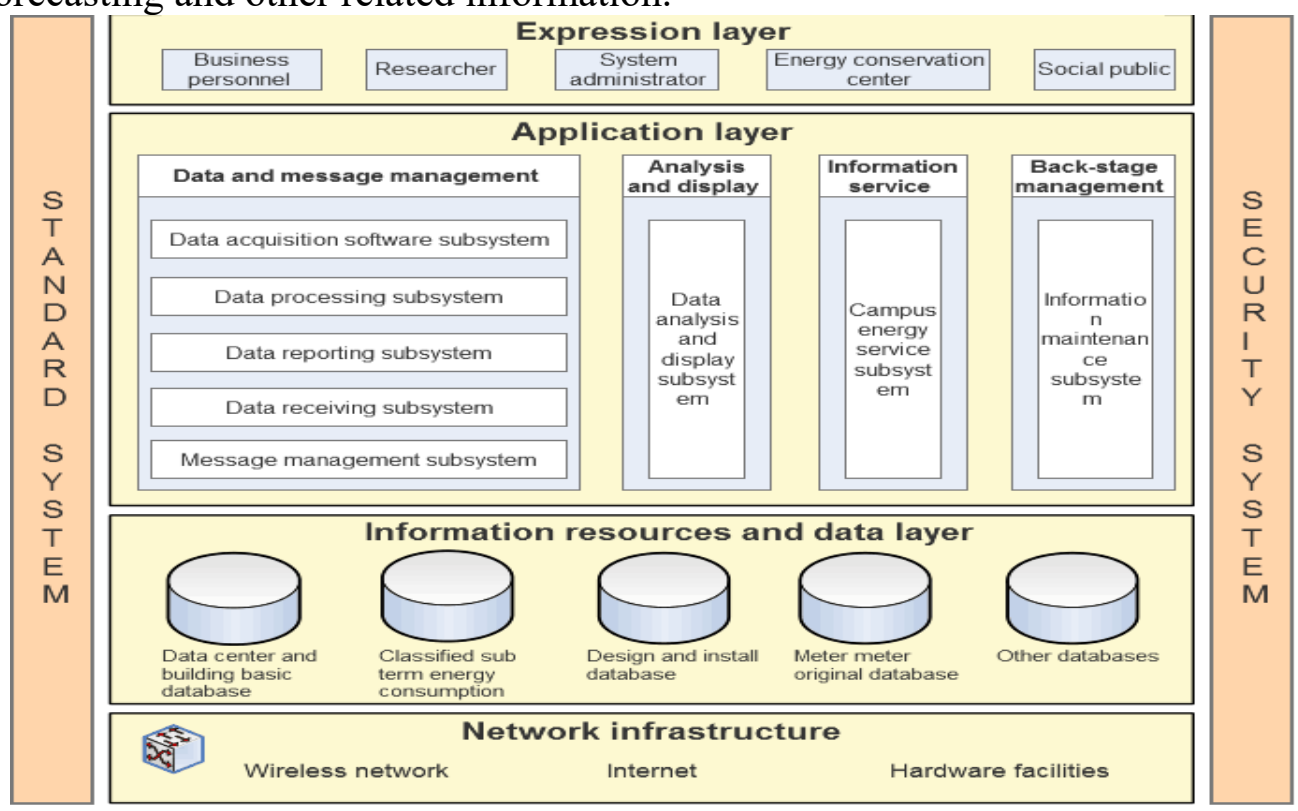

Fig. 2 Green campus energy efficiency monitoring system software layered architecture

The system software mainly has the following functions:

Project Overview

Energy consumption detecting

Energy analysis

Energy consumption publicity

Energy consumption alarm

Energy consumption report

Energy consumption forecast

Taking into account the actual distribution of the school meter, the system hardware that energy-consuming acquisition system will use two ways in connections and networking, the topology as shown below: 


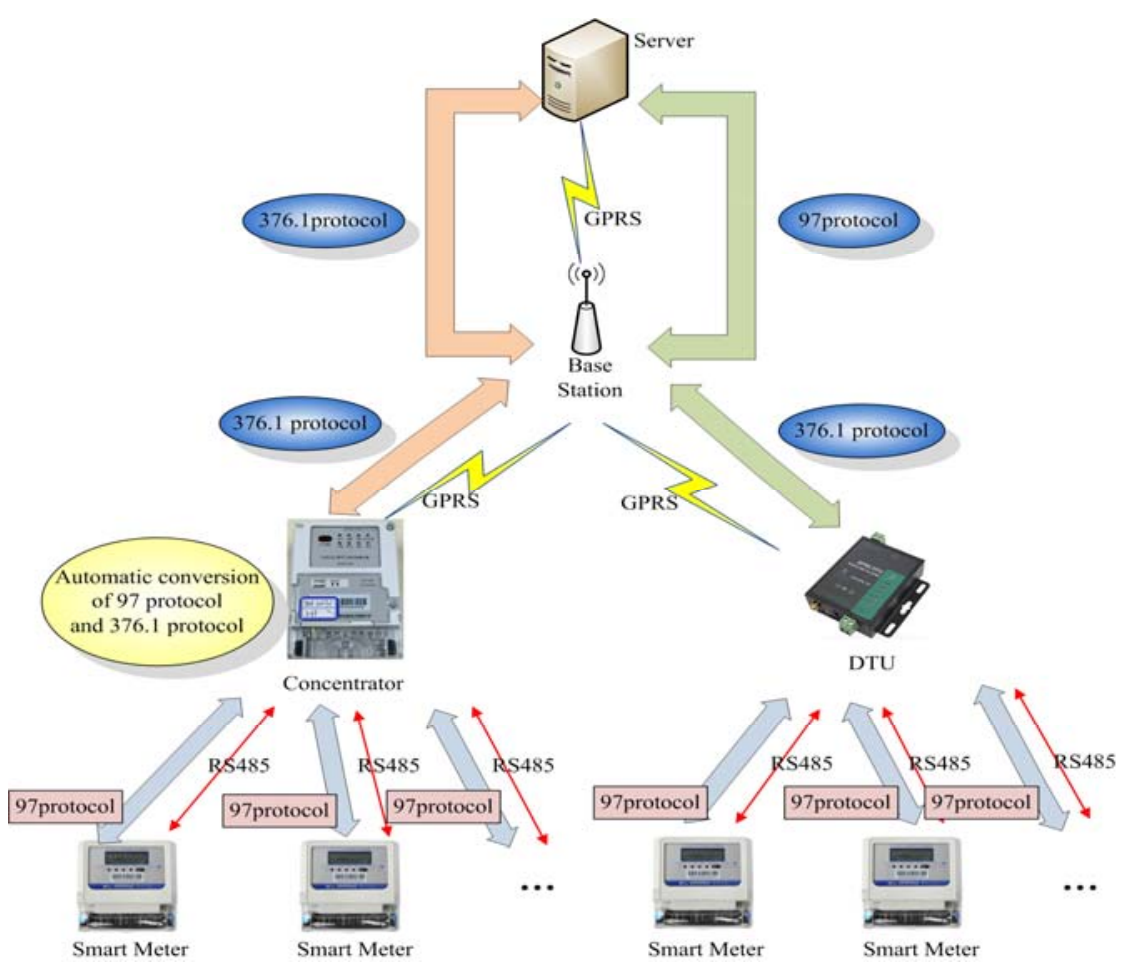

Fig. 3 System hardware topology

The main technical route adopted by the system:

The component technology of object-oriented

The component technology of object-oriented is an environment which is completely independent of hardware and operating system, it focuses on developing reusable components that make up the business "business object" of an application that enables the smooth setup of distributed applications. Application platform modules are relatively independent, the interface is clear, the internal business process upgrade and transformation has nothing to do with other modules, all modules based on components such as EJB, Web Services development, pluggable, and development API for the future development.

Physics-based three-tier structure

Application system platform development and operation of the structure to be based on the back-end database of the three-tier architecture, that is, Web application server, middleware application server and database server, any application server needs access to database services through middleware application server, and can be Web application servers, middleware application servers and database servers are deployed in different VLANs to enhance security.

Isolated architecture design

The architecture Design of Object-Oriented: Ensuring the structural, flexibility and reusability of software architecture from architecture design through abstraction, encapsulation, modularization and layering. Concerned about the separation of architecture design: Through the design pattern of layering, aspect-oriented and container, the relationship between requirements and architecture analysis in the interwoven and chaotic software elements is clarified so that the different interested areas are segmented and independent, thus achieving the divide and rule. Through object-oriented and separation of design ideas and related implementation techniques, the technology architecture and its supporting enterprise-wide industry applications can be as good as possible with a clear, well-defined hierarchy that encapsulates changes with sufficient flexibility and reusability ability.

Multi-heterogeneous hardware integration

The meter collection system and DTU-based data upload system involved in the system are all typical embedded systems. They are a combination of software and hardware and involve many autonomous and heterogeneous hardware and bus systems such as multi-function electricity meters, Concentrator, server, development board, 485 bus and so on. Software needs to be based on the hardware platform, the hardware part of the work includes the choice of embedded microprocessors 
and the choice of peripheral hardware circuits, the environment set up and the interconnection of many hardware devices. The software part of the work includes the choice of the appropriate operating system for transplantation and design and development of high stability embedded communications software.

\section{Summary}

Green Campus Energy Efficiency Monitoring System is an indispensable part of modern intelligent management platform of building by obtaining energy consumption data of buildings, scientifically analyzing energy consumption structure and trend and optimizing energy-saving strategies to assist in building energy-saving control. The system has adequate management value and application significance on improving the acquisition, storage, management and utilization of building energy data, optimizing the energy management process, establishing an objective energy consumption evaluation system, reducing the operating cost of energy utilization system and effectively reducing the building energy consumption. The system is one of the important tools for energy-saving, and building managers are the core strength of building energy-saving. With building energy efficiency monitoring system, for characteristic of different buildings, achieving building energy-saving is a process of continuous adjustment, feedback and optimization.

\section{References}

[1]. Rojali, Salman A G. Reversible Data Hiding Technique on Jpeg Image By Quad-Tree Segmentation and Histogram Shifting Method Based On Android[J]. Procedia Computer Science, 2015, 59:530-539.

[2]. Design of Embeded Remote Image Monitoring System Based on STM32[J]. Industrial Control Computer, 2016.

[3]. Kaseridis D, Iqbal M F, John L K. Cache Friendliness-Aware Managementof Shared Last-Level Caches for HighPerformance Multi-Core Systems[J]. IEEE Transactions on Computers, 2014, 63(4):874-887.

[4]. Winiarski D W, Jiang W, Halverson M A. Review of Pre- and Post-1980 Buildings in CBECS HVAC Equipment[J]. Technical Report, 2006.

[5]. Mills E. Action-oriented Benchmarking: Using the CEUS Database to Benchmark Commercial Buildings in California[J]. Energy Engineering, 2008, 105(Fall 2008):6-18. 